Olivet Nazarene University

Digital Commons @ Olivet

Pence-Boyce STEM Student Scholarship

Summer 2019

\title{
Study of Blood Viscosity with Added Sodium Nitrate and Temperature Variance: A Potential Therapy to Regulate Blood Flow After Induced Hypothermia
}

Brianna Munnich

Olivet Nazarene University, bvmunnich@olivet.edu

Follow this and additional works at: https://digitalcommons.olivet.edu/pence_boyce

Part of the Biochemistry Commons, Medical Biochemistry Commons, and the Medicinal and Pharmaceutical Chemistry Commons

\section{Recommended Citation}

Munnich, Brianna, "Study of Blood Viscosity with Added Sodium Nitrate and Temperature Variance: A Potential Therapy to Regulate Blood Flow After Induced Hypothermia" (2019). Pence-Boyce STEM Student Scholarship. 7.

https://digitalcommons.olivet.edu/pence_boyce/7

This Thesis is brought to you for free and open access by Digital Commons @ Olivet. It has been accepted for inclusion in Pence-Boyce STEM Student Scholarship by an authorized administrator of Digital Commons @ Olivet. For more information, please contact digitalcommons@olivet.edu. 


\title{
Study of Blood Viscosity with Added Sodium Nitrate and Temperature Variance:
}

\section{A Potential Therapy to Regulate Blood Flow After Induced Hypothermia}

Brianna Munnich \& Dr. Willa Harper

Department of Chemistry and Geosciences

Pence-Boyce Research Experience

Olivet Nazarene University, Bourbonnais, IL

\begin{abstract}
The human body has natural systems for vasodilation which are fueled by nitric oxide production, but in cases of cardiac disfunction and stress nitric oxide can be inhibited. In this study, nitric oxide was studied as a mediator for the blood rush experienced from the warming after induced hypothermia. Nitric oxide (NO) was introduced through sodium nitrate, which was aimed to reduce the speed and turbulence of blood flow through interaction between NO and the active site of hemoglobin. A viscometer was used to examine the rate of blood flow, while the temperature was varied to simulate the conditions of induced hypothermia. Two temperatures were tested to simulate the warming following induced hypothermia, and three concentrations of sodium nitrate were added to the samples to examine the correlation between flow and concentration. The results indicated that the $0.11 \mathrm{M} \mathrm{NaNO}_{3}$ expressed constant blood viscosity for both temperatures, the $0.09 \mathrm{M} \mathrm{NaNO}_{3}$ exhibited some mediation, and the $0.10 \mathrm{M}$ showed the least mediation.
\end{abstract}

\section{Therapeutic Hypothermia}

Therapeutic cooling has been employed in medicine for a very long time, but with varied results. In recent years, several studies have examined induced hypothermia as a treatment after cardiac arrest. These studies have concluded that cooling patients slows tissue damage caused from cardiac trauma $[1,2]$. Therapeutic hypothermia, however, contributes to a high mortality 
rate, and many patients who do survive the procedure are left with neurological deficits. A study conducted at the Central Lisbon Hospital Center, in Portugal, used induced hypothermia on ICU patients and yielded a $61 \%$ mortality rate [3]. Hemorrhage and increased blood loss were hypothesized as possible causes for this percentage [3,4]. Another study specifically examined blood effects from induced hypothermia in perioperative patients and indicated that blood loss was increased by $16 \%$ [5]. The increased blood loss was likely the result of the blood rush during the hypothermia reversal process. In several cases, it was observed that as the blood was warmed, it reacts drastically due to blood shear thinning properties, leading to a blood rush $[1,5]$. This is a biological representation of the inverse relationship between viscosity and temperature, which is foreign to the human system. The blood rush can yield brain damage and added stress to an already pressured cardiac system. This blood rush has been noted to occur even when the warming and cooling processes are done at a very slow rate. In each of the studies referenced, the heating and cooling process took approximately 24 hours; however, the effects of the blood rush were still present $[3,4]$. If the rush could be controlled, it might make induced hypothermia a much more successful procedure.

\section{Nitric Oxide}

Nitric oxide (NO) plays a key physiological role in the cardiovascular, respiratory, digestive, immune, and nervous systems [6]. NO acts as a cardiovascular stimulant which relaxes the vessels and fuels the pacemaker $[7,8,9]$. The NO molecule is produced in the endothelium of the blood vessels from the conversion of arginine to citrulline when the cardiac system is healthy [6]. Plaque buildup in the vessels can severely impair the ability of nitric oxide to be released [7, 10]. Since plaque is a major cause of cardiac disfunction, it is likely that many patients treated with induced hypothermia for cardiac arrest would have plaque hindering their ability to produce 
NO [7]. For this reason, an introduction of nitric oxide into the circulatory system during the warming process of induced hypothermia may work to normalize blood flow and contribute to restoring the body's natural homeostasis. As the core temperature is raised, vasodilation and sweating are required for heat to dissipate, and the vasodilator responsible for this is NO. A study examining the blood flow to the skin noted that nitric oxide contributes $30 \%$ of the vasodilation reflex experienced in the body when heat is dissipated during core cooling [11]. In another study, scientists evaluated the amount of NO required by the body to achieve normal blood flow and discovered that patients with worse health or heart strain required more NO to propel normal circulation [7]. Nitric oxide also has been shown to work in the prevention of plaque in the circulatory system, which could aid in the long-term rehabilitation of cardiac arrest patients [7].

\section{Pharmaceutical Use of Nitric Oxide}

Sodium nitrate is an organic salt that is utilized in several medications to introduce nitric oxide into the circulatory system. Nitrodilators, which contain sodium nitrate, are currently used to relax the blood vessels of hypertensive patients [12]. Sodium nitrate itself has been used in patients to prevent cardiac arrest [13]. Sodium nitrate dissociates in vivo to release nitric oxide, sodium ions, and diatomic oxygen. Nitric oxide and sodium are diffused out of the bloodstream in milliseconds; the oxygen, however, is not [14]. Oxygen remains in the blood much longer than the nitric oxide because the NO molecule binds to the allosteric site of the heme group in hemoglobin, reducing its ability to bind oxygen [15]. Saturating the blood with oxygen over a long period of time can be dangerous; therefore, a sodium nitrate treatment would only need to be used in targeted cases for short durations $[15,16]$. Also, in many cases, patients treated with sodium nitrate quickly became accustomed to the treatment, and it no longer yielded an effect [12]. Therefore, employing sodium nitrate as a long-term medication would likely be fruitless. 
Studies have not yet explored the benefits of one-time intravenous treatments with sodium nitrate for therapeutic hypothermia. The controlled environment required for induced hypothermia would aid in controlling the oxygen levels of the patients. This could prevent saturation, making the introduction of sodium nitrate safer.

\section{Experimental Development}

The current uses of sodium nitrate in medicine point towards a potential application in the blood warming process after induced hypothermia. While there are some negative associations connecting high levels of nitrates to cancer, the NO molecule only exists in the blood for milliseconds; therefore, the use of sodium nitrate is feasible in specialized procedures $[14,17]$. This study hypothesized that sodium nitrate would regulate human blood flow when the blood was warmed to mitigate the blood rush and bring the flow back to normal. The experiment was done to determine the interaction between the red blood cells (RBCs) and nitric oxide. The effect of NO on blood flow was measured by viscosity. Blood flow was analyzed in this study using a Zahn cup viscometer at targeted temperatures to simulate induced hypothermia. Defibrinated sheep blood was used, and samples were tested both without sodium nitrate and with three different concentrations of sodium nitrate.

\section{Methodology}

Defibrinated sheep blood was obtained for testing and stored at approximately $1^{\circ} \mathrm{C}$.

Under these conditions, the blood has a shelf life of 28 days. The blood was defibrinated mechanically by the manufacturer, Quad Five, and was verified for purity by the USDA [18].

Defibrinated blood is free of anticoagulants that can interfere with observation of the experimentally-induced effects on the blood viscosity. Defibrinated sheep blood has been 
certified to be a viable substitute for human blood in diagnostic testing and is used by many companies for experimentation [19].

The Zahn Cup viscometer, size two, was used to measure viscosity. The size two Zahn cup has an orifice size of 0.108 inches and a capacity of 44 milliliters. This was used in the calculation of shear rate [20]. Zahn Cup viscometers are used to measure the viscosity of a fluid via the time of efflux through the orifice. This brand of viscometer is often used to measure the viscosity of paint. Paint is a non-Newtonian, shear thinning, fluid similar to blood, so the Zahn Cup viscometer should give applicable results for blood viscosity. The design of the Zahn Cup employs gravity for viscosity measurements, an ideal aid in reducing added turbulence in the samples [21].

The recommended temperature for use with Zahn cup viscometers is $25^{\circ} \mathrm{C}$. However, a calibration curve can also be made with a control liquid and careful monitoring of the temperature as per the instructions of the manufacturer [20]. A calibration curve was constructed for this experiment. Defibrinated sheep blood without sodium nitrate was the control standard. Three trials were taken for each temperature tested, with the average being used to form the curve. The range of temperature was set from $25^{\circ} \mathrm{C}$ to $37^{\circ} \mathrm{C}$ with trials beginning at the highest temperature. $37^{\circ} \mathrm{C}$ was set as the upper bound to account for the warming to normal human body temperature. $25^{\circ} \mathrm{C}$ was used for cooling and was chosen from the recommended temperatures for the Zahn Cup viscometer, as per the manufacturer's guide [20]. Since this temperature is five degrees lower than the usual minimum cooling for induced hypothermia, this was assumed to give a reasonable result for the minimum bound of the data range.

To begin, blood samples were raised from refrigeration to room temperature, approximately $22^{\circ} \mathrm{C}$. The temperature was then raised slowly to $37^{\circ} \mathrm{C}$ using a warm water bath 
with temperature control. The bath was raised in increments of $5^{\circ} \mathrm{C}$, allowing the blood to acclimate to the temperature slowly. This prevented the blood from denaturing. When it reached $37^{\circ} \mathrm{C}$, the first reading was measured. Readings were taken at each degree increment as the blood was cooled to $24^{\circ} \mathrm{C}$. An ice bath was used for cooling.

Readings were taken by submerging the Zahn Cup in the blood and allowing it to warm. Once the viscometer had warmed to temperature, the cup was raised to just under the top of the blood. The cup was then raised vertically six inches and placed on a hook set over the center of the collection beaker. A stopwatch was started as the cup broke the surface of the blood and was stopped when the first break in the flow of the blood was observed [20]. Between each reading, the Zahn cup was rinsed to prevent cohesion which could alter the flow time. The Zahn cup was cleaned completely between each sample to avoid contamination.

Sodium nitrate solutions were made by diluting the salt in water. The amount of sodium nitrate needed was calculated using the concentration of salt administered in a typical IV bag of sodium chloride given for dehydration [22]. The calculated concentration was $0.10 \mathrm{M} \mathrm{NaNO}_{3}$. The concentrations of $0.09 \mathrm{M}$ and $0.11 \mathrm{M} \mathrm{NaNO}_{3}$ were also tested to account for the difference in molecular weight of sodium nitrate and sodium chloride and to account for different rates of dissociation for each salt in the blood. Ten trials were run at each sodium nitrate concentration for both $25^{\circ} \mathrm{C}$ and $37^{\circ} \mathrm{C}$. The average of these ten trials, excluding major outliers, were considered in the final analysis of viscosity. Outliers were categorized as any values which were \pm 0.20 seconds away from the closest flow time.

All blood and instruments were handled using medical grade gloves and goggles. These safety procedures ensured that the blood was not contaminated during testing, and samples were disposed of properly using biohazard procedures. All beakers and utensils which touched blood 
were cleaned with appropriate procedures between each change of concentration and temperature in the experiment.

\section{Results}

\begin{tabular}{|c|c|c|c|}
\hline \multicolumn{4}{|c|}{$\begin{array}{l}\text { TABLE 1. CONTROL TEMPERATURE CURVE } \\
\text { DATA FOR BLOOD WITH NO SODIUM NITRATE }\end{array}$} \\
\hline $\begin{array}{l}\text { TEMP. } \\
\left({ }^{\circ} \mathrm{C}\right)\end{array}$ & $\begin{array}{c}\text { Flow Time } \\
\text { (sec) }\end{array}$ & $\begin{array}{c}\mathrm{DV} \\
(\mathrm{PA} \cdot \mathrm{s})\end{array}$ & $\begin{array}{c}\text { Shear Rate } \\
(1 / \mathrm{s})\end{array}$ \\
\hline 25 & 15.18 & $4.4 \times 10^{-3}$ & 1.22 \\
\hline 26 & 15.10 & $4.1 \times 10^{-3}$ & 1.23 \\
\hline 27 & 14.96 & $3.6 \times 10^{-3}$ & 1.24 \\
\hline 28 & 14.93 & $3.5 \times 10^{-3}$ & 1.24 \\
\hline 29 & 14.94 & $3.5 \times 10^{-3}$ & 1.24 \\
\hline 30 & 14.89 & $3.3 \times 10^{-3}$ & 1.26 \\
\hline 31 & 14.80 & $3.0 \times 10^{-3}$ & 1.26 \\
\hline 32 & 14.58 & $2.1 \times 10^{-3}$ & 1.27 \\
\hline 33 & 14.64 & $2.4 \times 10^{-3}$ & 1.27 \\
\hline 34 & 14.64 & $2.4 \times 10^{-3}$ & 1.27 \\
\hline 35 & 14.80 & $2.9 \times 10^{-3}$ & 1.25 \\
\hline 36 & 14.77 & $2.9 \times 10^{-3}$ & 1.26 \\
\hline 37 & 14.60 & $2.2 \times 10^{-3}$ & 1.27 \\
\hline
\end{tabular}

The results in Table 1

show the gathered data for the control curve. From $25^{\circ} \mathrm{C}$ to $32^{\circ} \mathrm{C}$, a decreased dynamic viscosity (DV) occurs as the temperature increases. From $32^{\circ} \mathrm{C}$ to $37^{\circ} \mathrm{C}$, a blood rush appears with an increase in dynamic viscosity, followed by a quick reduction to the minimum dynamic viscosity.

\section{Apparent Viscosity}

The apparent viscosity is a comparison of the dynamic viscosity to the rate at which the fluid shears. Apparent viscosity is used to model non-Newtonian fluids which do not have a constant shear rate. Blood is a shear-thinning fluid so it should be modeled with apparent viscosity [21]. This is because blood aggregates due to its colloidal structure. For each concentration and 
temperature tested, the apparent viscosity was tabulated and evaluated in Pascal seconds. The ranges seen in the apparent viscosity across the trials indicate the influence of temperature on the shear stress, which causes turbulence in the sample.

\section{Calculation of Dynamic Viscosity}

Kinematic viscosity (KV) was calculated using the formula provided with the Zahn cup viscometer: $\mathrm{KV}=3.5$ (t-14); where 3.5 and 14 are unitless constants [20]. To convert from $\mathrm{KV}$, (measured in $\mathrm{m} \mathrm{Pa} \cdot \mathrm{s}$ ) to dynamic viscosity (DV), the kinematic viscosity was multiplied by the density of blood $(\rho), 1.06 \mathrm{~g} / \mathrm{m}^{3}$ [23]. Lastly, the dynamic viscosity was converted to Pa.s for comparison with the values of normal blood viscosity, $3.0 \times 10^{-3}$ and $4.0 \times 10^{-3}$ [24].

\section{Sample Calculation of Dynamic Viscosity}

Calculation was done using the flow time of 15.18 seconds from the $25^{\circ} \mathrm{C}$ control trial.

$$
\begin{aligned}
& K V=3.5(t-14) \\
& K V=3.5(15.18-14) \quad K V=4.13 \mathrm{mPa} \cdot \mathrm{s} \\
& D V=\rho \times K V \quad D V=1.06(4.13) \quad D V=4.3778 \mathrm{mPa} \cdot \mathrm{s} \\
& 1 \mathrm{~Pa} \cdot \mathrm{s}=1,000 \mathrm{mPa} \cdot \mathrm{s} \quad D V=\frac{4.3778}{1,000} \quad D V=4.4 \times 10^{-3} \mathrm{~Pa} \cdot \mathrm{s}
\end{aligned}
$$

\section{Calculation of Control Shear Rate for Expressing Apparent Viscosity}

The shear rate was calculated by dividing the velocity in $\mathrm{m} / \mathrm{s}$ by the height the blood fell from the top of the Zahn cup to the blood's exit at the orifice. These measurements were obtained from the instructions provided with the Zahn cup size two viscometer [20]. 


\section{Sample Calculation of Shear Rate}

Calculation was done using the flow time of 15.18 seconds from the $25^{\circ} \mathrm{C}$ control trial.

Velocity of Blood Flow $=\frac{\text { height of blood fall }(\mathrm{m})}{\text { flow time }(\mathrm{sec})} \quad$ Velocity $=\frac{0.0508}{15.18}=3.3 \times 10^{-3} \mathrm{~m} / \mathrm{s}$

Shear rate $=\frac{\text { velocity }\left(\frac{m}{s}\right)}{\text { height of the zahn cup }(m)} \quad$ Shear rate $=\frac{3.3 \times 10^{-3}}{0.00274} \quad$ Shear rate $=1.221 / \mathrm{s}$

Considerations for Result Interpretation

The data taken for the $0.09 \mathrm{M} \mathrm{NaNO}_{3}, 0.10 \mathrm{M} \mathrm{NaNO}_{3}$, and $0.11 \mathrm{M} \mathrm{NaNO}_{3}$ are represented as averages taken from the ten trials taken at $25^{\circ} \mathrm{C}$ and $37^{\circ} \mathrm{C}$. The averages were calculated while excluding major outliers. Outliers in this experiment are designated as any values which were within a \pm 0.20 separation of flow time data. Outliers were removed to account for the human error caused from lifting the Zahn cup improperly or timing errors. Human error was also minimized by repeating the runs ten times until values were repeated or had very little deviation. Frequently, values will be compared to normal human blood viscosity which is between $3.0 \times 10^{-3}$ and $4.0 \times 10^{-3} \mathrm{~Pa} \cdot \mathrm{s}$ at $37^{\circ} \mathrm{C}[24]$.

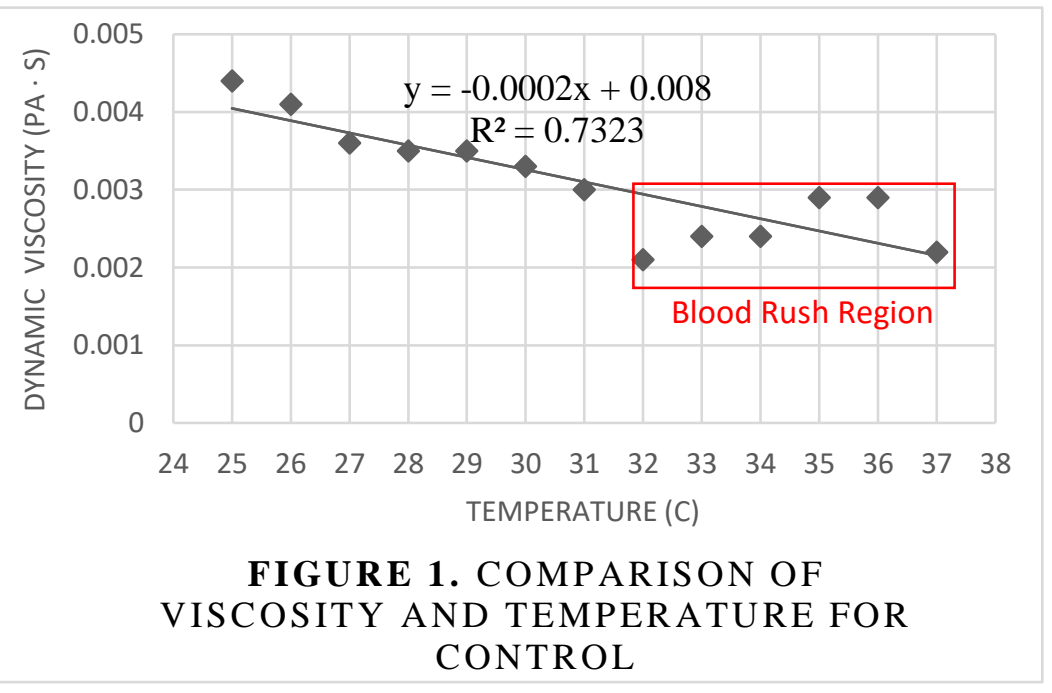

In Figure 1, the control data was plotted as the calculated DV versus the temperature. The trendline obtained from the control curve was used to determine the deviation of the sodium nitrate 
trials. This plot was also constructed in order to determine if the experimental model exhibited the expected trend without a changed variable.

The data in Figure 1 exhibited the expected relationship between the viscosity of the blood and the temperature. Turbulence in the sample was also observed in the control trials from $32^{\circ} \mathrm{C}$ to $37^{\circ} \mathrm{C}$, as described in the literature. Between $31^{\circ} \mathrm{C}$ and $32^{\circ} \mathrm{C}$, a dramatic decrease is observed in the dynamic viscosity, which brings it to nearly $1 \times 10^{-3} \mathrm{~Pa} \cdot \mathrm{s}$ below the range of

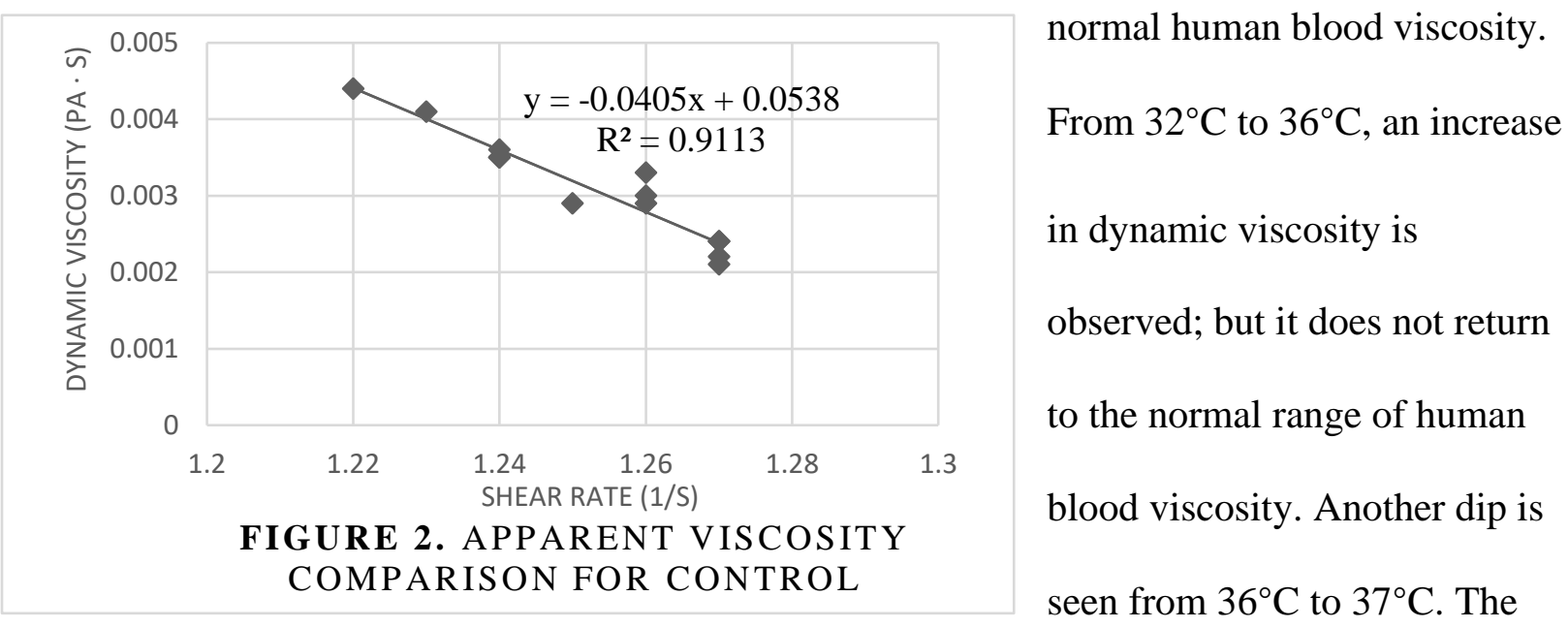

dynamic viscosity at $37^{\circ} \mathrm{C}$ lies below the range for normal human blood viscosity and is likely a result of two factors. These factors are the lack of vessel-induced friction in the experimental model and the blood rush phenomenon increasing shear stress (which is higher than the other samples) and eddies in the blood samples. Figure 2 expresses the apparent viscosity through the comparison of the dynamic viscosity and the shear rate of the blood flow for the control temperatures. The trendline on this plot was used to evaluate deviations in further comparisons of the trials employing sodium nitrate.

In Figure 3, each concentration of sodium nitrate is compared by apparent viscosity for the $25^{\circ} \mathrm{C}$ trials. The minimum, maximum, and average for each concentration are depicted along 
with trendlines to express the turbulence of the blood samples. The $0.09 \mathrm{M} \mathrm{NaNO}_{3}$ had the highest viscosity range due to higher maximum, minimum, and average values. The trendline

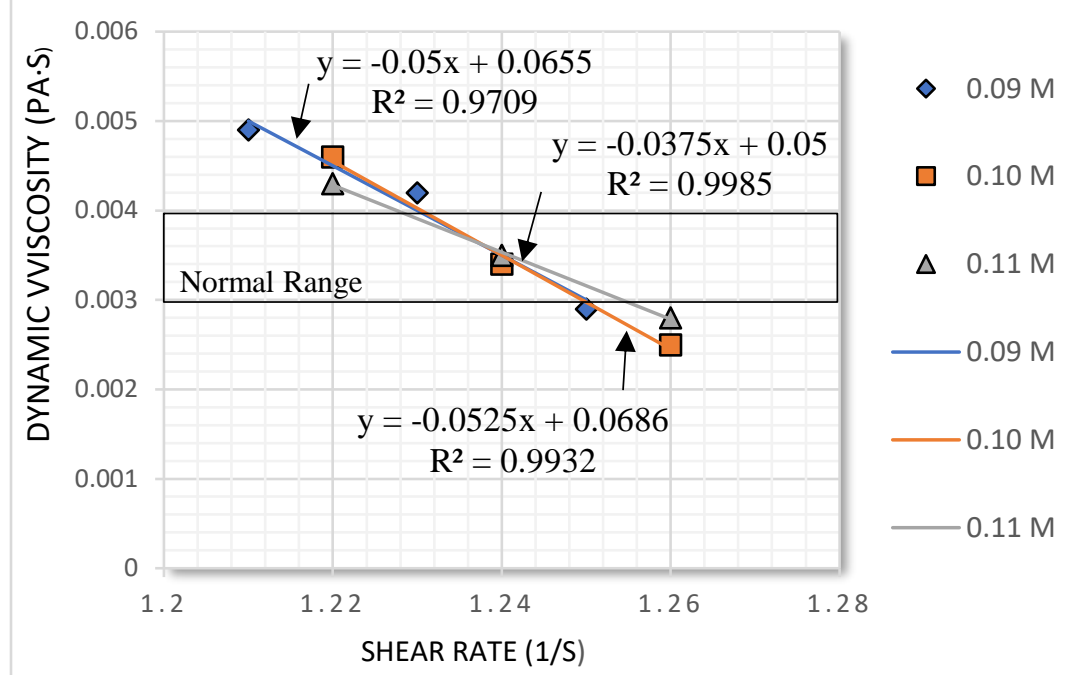

FIGURE 3. APPARENT VISCOSITY FOR VARYING CONCENTRATIONS OF SODIUM NITRATE AT $25^{\circ} \mathrm{C}$ does not include the average marker, likely indicating that this concentration of sodium nitrate experienced some turbulence. The $\mathrm{R}^{2}$ value for the $0.09 \mathrm{M}$ sample was slightly lower than expected from the fits of the other two concentrations, and the 0.10

$\mathrm{M}$ and $0.11 \mathrm{M}$ showed better correlation to normal DV values for human blood. The trials employing $0.10 \mathrm{M} \mathrm{NaNO}_{3}$ and the $0.11 \mathrm{M} \mathrm{NaNO}_{3}$ had similar ranges and averages, with little deviation, and each trendline contains all three data points. The $\mathrm{R}^{2}$ values for these two concentrations also indicate a strong correlation with blood flow and low turbulence. The $0.10 \mathrm{M}$ slope is steeper than that of $0.11 \mathrm{M} \mathrm{NaNO}_{3}$, with a slope more consistent to that of the $0.09 \mathrm{M}$ concentration. The averages for the $0.10 \mathrm{M}$ and the $0.11 \mathrm{M}$ concentrations fell within the range for normal human blood viscosity. The ranges for the $0.10 \mathrm{M}$ and $0.11 \mathrm{M}$ trials were narrower than that of the $0.09 \mathrm{M}$ trial, with the $0.11 \mathrm{M}$ having the narrowest range. The ranges for each of the concentrations exceed the limits for normal human blood viscosity on the upper and lower bound, but show linear trends indicating little to no turbulence in the blood samples. 
Table 2. Apparent Viscosity of Various Concentrations of $\mathrm{NaNO}_{3}$ at $25^{\circ} \mathrm{C}$

\begin{tabular}{l|ccc} 
& Avg. Flow Time (s) & Avg. DV (Pa·s) & Shear rate (1/s) \\
$0.09 \mathrm{M} \mathrm{NaNO}_{3}$ & 15.12 & $4.2 \times 10^{-3}$ & 1.22 \\
$0.10 \mathrm{M} \mathrm{NaNO}_{3}$ & 14.87 & $3.3 \times 10^{-3}$ & 1.25 \\
$0.11 \mathrm{M} \mathrm{NaNO}_{3}$ & 14.93 & $3.5 \times 10^{-3}$ & 1.24
\end{tabular}

In Table 2, the trends from Figure 3 are clearly defined. One can see from Figure 3 and Table 2 that the $0.09 \mathrm{M}$ sodium nitrate was the only concentration to lie outside of the normal range for human blood viscosity at $25^{\circ} \mathrm{C}$ for both temperatures and the average. Table 2 illustrates the inverse relationship between the shear rate and the dynamic viscosity and clarifies the averages seen in the $0.10 \mathrm{M}$ and $0.11 \mathrm{M}$ concentrations, which are tightly packed in Figure 3. The average dynamic viscosity for the $0.10 \mathrm{M}$ concentration of sodium nitrate is the lowest of the three trials at $25^{\circ} \mathrm{C}$, but it is still very close to the value calculated for the $0.11 \mathrm{M}$ concentration. The $0.10 \mathrm{M}$ and $0.11 \mathrm{M}$ concentrations are extremely close in values, while the 0.09 $\mathrm{M}$ concentration is slightly higher for each benchmark.

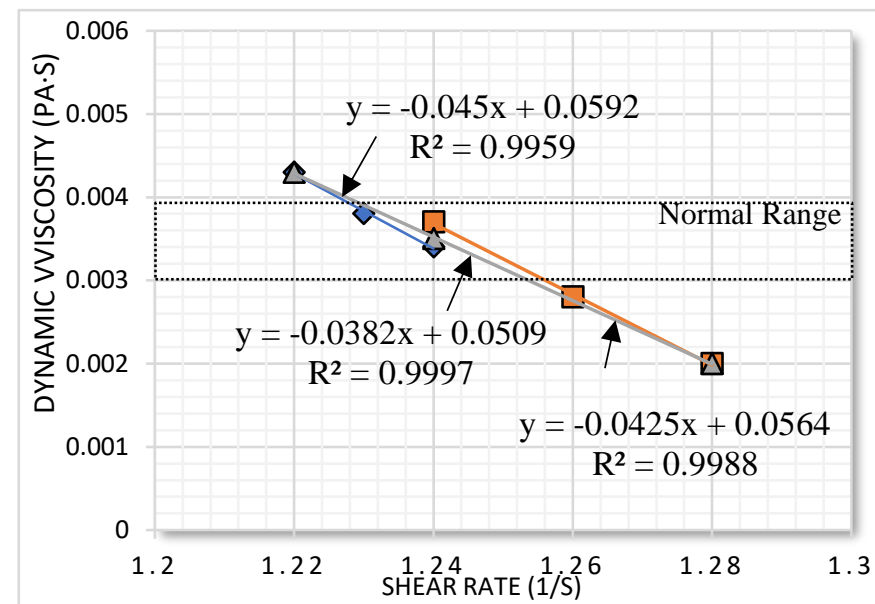

FIGURE 4. APPARENT VISCOSITY FOR VARYING CONCENTRATIONS OF SODIUM NITRATE AT $37^{\circ} \mathrm{C}$ $\diamond 0.09 \mathrm{M}$

$0.10 \mathrm{M}$

$\Delta \quad 0.11 \mathrm{M}$

$0.09 \mathrm{M}$

$-0.10 \mathrm{M}$ $0.11 \mathrm{M}$ to represent the warming phase of induced hypothermia. The minimum, maximum, and

In Figure 4, the apparent viscosity is compared for each concentration of sodium nitrate at $37^{\circ} \mathrm{C}$, the temperature chosen 
average for each concentration are depicted with trendlines to express the flow of the blood samples. The $0.09 \mathrm{M}$ concentration had a very narrow range, with nearly all points within the normal range or without significant deviation. The $0.10 \mathrm{M}$ concentration had more deviation between its maximum and minimum, and only its maximum was within the normal range for human blood viscosity. The $0.11 \mathrm{M}$ concentration had the largest deviation in its range, but its average was within the area for normal human blood viscosity. The maximum and average portions of the ranges were within normal human blood viscosity for the $0.09 \mathrm{M}$ and $0.11 \mathrm{M}$ concentrations. The minima for the $0.10 \mathrm{M}$ and $0.11 \mathrm{M}$ fell below the normal range for human blood viscosity.

Table 3. Apparent Viscosity of Various Concentrations of $\mathrm{NaNO}_{3}$ at $37^{\circ} \mathrm{C}$

\begin{tabular}{l|ccc} 
& Avg. Flow Time (s) & Avg. DV (Pa·s) & Shear rate (1/s) \\
$0.09 \mathrm{M} \mathrm{NaNO}_{3}$ & 15.03 & $3.8 \times 10^{-3}$ & 1.23 \\
$0.10 \mathrm{M} \mathrm{NaNO}_{3}$ & 14.76 & $2.8 \times 10^{-3}$ & 1.26 \\
$0.11 \mathrm{M} \mathrm{NaNO}_{3}$ & 14.93 & $3.5 \times 10^{-3}$ & 1.24
\end{tabular}

In Table 3, the average values at $37^{\circ} \mathrm{C}$ are expressed to clarify between close values in

Figure 4. Table 3 shows that the $0.09 \mathrm{M}$ and $0.11 \mathrm{M}$ concentration were closer in average value than the $0.10 \mathrm{M}$ concentration. The $0.10 \mathrm{M}$ concentration had the lowest dynamic viscosity and was the only concentration that had an average below the normal value for human blood viscosity.

In Figure 5, the average dynamic viscosities were plotted to show the change between 25 ${ }^{\circ} \mathrm{C}$ and $37^{\circ} \mathrm{C}$ for each of the concentrations of sodium nitrate and the control. The slopes of each sample indicate whether the viscosity change was mediated during the warming of the blood. The control sample had the largest variance in dynamic viscosity with a range from 
$4.4 \times 10^{-4}$ to $2.2 \times 10^{-4}$ and a net change of $2.2 \times 10^{-3}$. The $0.10 \mathrm{M} \mathrm{NaNO}_{3}$ had the next largest

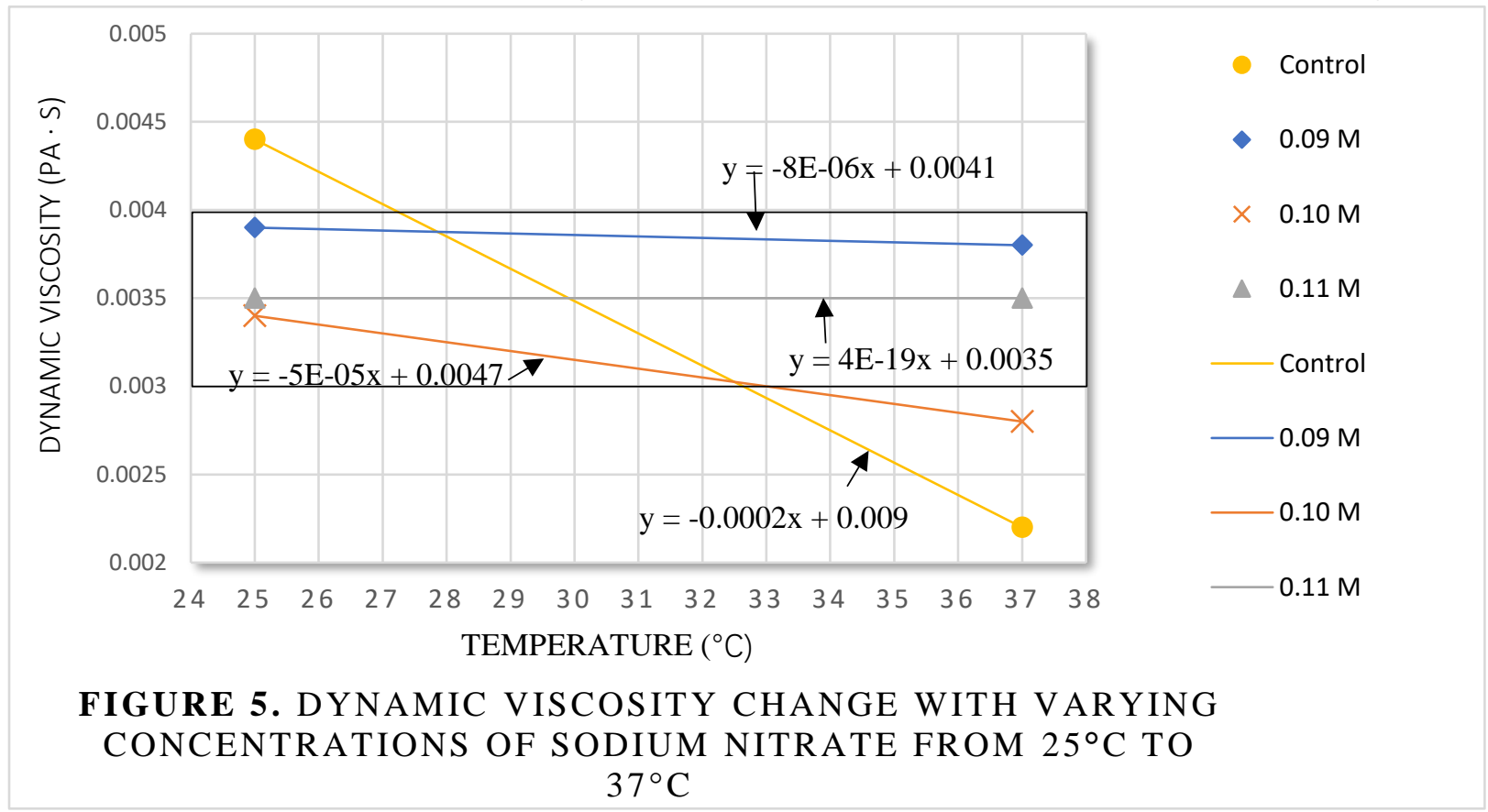

change in dynamic viscosity over the two temperatures with a change of $6.0 \times 10^{-4}$ which was still much lower than the change seen in the control sample. This was the largest variance for the sodium nitrate trials, and it ended with a dynamic viscosity that is not within the range of normal human blood viscosity. The $0.09 \mathrm{M}$ and $0.11 \mathrm{M}$ concentrations show relatively little change over the temperature range. The $0.09 \mathrm{M}$ concentration had a net change of $1.0 \times 10^{-4}$ and the $0.11 \mathrm{M}$ concentration showed no change. The $0.09 \mathrm{M}$ and $0.11 \mathrm{M}$ concentrations of sodium nitrate both lie within the range for normal human blood viscosity at $25^{\circ} \mathrm{C}$ and $37^{\circ} \mathrm{C}$.

In Table 4, the results of the graph are tabulated into calculations to more precisely differentiate between the different trials at the two temperatures tested. The $0.09 \mathrm{M}$ and $0.11 \mathrm{M}$ concentrations had a larger deviation in slope from the control with the values $1.92 \times 10^{-4}$ and $1.99 \times 10^{-4}$, respectively. A slightly smaller deviation was observed in the $0.10 \mathrm{M}$ concentration $\left(1.50 \times 10^{-4}\right)$, but the value is still close to those of the $0.09 \mathrm{M}$ and the $0.11 \mathrm{M}$ concentrations. At $25^{\circ} \mathrm{C}$, the deviation for the $0.10 \mathrm{M}$ concentration is larger than those for the $0.09 \mathrm{M}$ and 0.11 
$\mathrm{M}$ concentration by a magnitude of 10 . The $0.09 \mathrm{M}$ and $0.10 \mathrm{M}$ concentrations exhibit a smaller change at the $25^{\circ} \mathrm{C}$ temperature, as shown by their higher values when cooled. Each of the concentrations tested at the warmed temperature, $37^{\circ} \mathrm{C}$, showed values of comparable magnitude with little deviation from each other.

Table 4. Deviation of Dynamic Viscosity (DV) from the Control as the Samples were Warmed

\begin{tabular}{|c|c|c|c|c|}
\hline & $\begin{array}{l}\triangle \mathrm{DV} \\
(\mathrm{Pa} \cdot \mathrm{s})\end{array}$ & $\begin{array}{c}\triangle \text { Slope } \\
(\mathrm{Pa} \cdot \mathrm{s})\end{array}$ & $\begin{array}{c}\triangle \mathrm{DV} \text { at } 25^{\circ} \mathrm{C} \\
(\mathrm{Pa} \cdot \mathrm{s})\end{array}$ & $\begin{array}{c}\triangle \mathrm{DV} \text { at } 37^{\circ} \mathrm{C} \\
(\mathrm{Pa} \cdot \mathrm{s})\end{array}$ \\
\hline $0.09 \mathrm{M} \mathrm{NaNO}_{3}$ & $1.0 \times 10^{-4}$ & $1.92 \times 10^{-4}$ & $5.0 \times 10^{-4}$ & $1.6 \times 10^{-3}$ \\
\hline $0.10 \mathrm{M} \mathrm{NaNO}_{3}$ & $6.0 \times 10^{-4}$ & $1.50 \times 10^{-4}$ & $1.0 \times 10^{-3}$ & $2.8 \times 10^{-3}$ \\
\hline $0.11 \mathrm{M} \mathrm{NaNO}_{3}$ & 0 & $1.99 \times 10^{-4}$ & $9.0 \times 10^{-4}$ & $1.3 \times 10^{-3}$ \\
\hline Control & $2.2 \times 10^{-3}$ & $\mathrm{n} / \mathrm{a}$ & $\mathrm{n} / \mathrm{a}$ & $\mathrm{n} / \mathrm{a}$ \\
\hline
\end{tabular}

\section{Analysis}

The control curve displayed in Figure 1 exhibited the expected pattern of increased viscosity at decreased temperature. At $32^{\circ} \mathrm{C}$, variation seen in the viscosity illustrates the turbulence in the sample, which was the focus of observation in the experiment. The viscosities at $25^{\circ} \mathrm{C}$ and $37^{\circ} \mathrm{C}$ are out of the range of normal human blood viscosity, so the results of the control are not optimal for comparison to the sodium nitrate trials. Therefore, slopes were examined more closely for comparison. The steep decrease in dynamic viscosity may have been caused by the lack of friction from the Zahn cup in comparison to a blood vessel.

The $0.09 \mathrm{M} \mathrm{NaNO}_{3}$ data showed some signs of mediation with a very small decrease in dynamic viscosity between the $25^{\circ} \mathrm{C}$ and $37^{\circ} \mathrm{C}$ measurements. At both tested temperatures, the dynamic viscosity for the $0.09 \mathrm{M} \mathrm{NaNO}_{3}$ stayed within the range of normal human blood 
viscosity. In comparison to the other trials, the $0.09 \mathrm{M}$ concentration of sodium nitrate was the second most effective at maintaining the constant viscosity during the warming of the blood.

The $0.10 \mathrm{M} \mathrm{NaNO}_{3}$ showed varied results, with a steeper decrease in dynamic viscosity when the temperature was raised than those of the other two concentrations of sodium nitrate. The dynamic viscosity at $25^{\circ} \mathrm{C}$ was within the range of normal human blood viscosity; but over the warming process, the dynamic viscosity was lowered to below the normal range for human blood viscosity. The dynamic viscosity for the $0.10 \mathrm{M} \mathrm{NaNO}_{3}$ was expected to lie between the $0.09 \mathrm{M}$ and $0.11 \mathrm{M}$ concentrations of sodium nitrate when measured at $25^{\circ} \mathrm{C}$, but it did not. This inconsistency may indicate a possible error in the experimental model.

The $0.11 \mathrm{M} \mathrm{NaNO}_{3}$ expressed the greatest amount of mediation, with an unchanging dynamic viscosity over the two temperatures tested. Both dynamic viscosity measurements taken lie within the range for normal human blood viscosity. It is hypothesized that more nitric oxide may be released for the higher concentrations of sodium nitrate, and that this may lead to greater mediation. The $0.10 \mathrm{M} \mathrm{NaNO}_{3}$ did not follow the pattern of this hypothesis, but it may be due to error in the $0.10 \mathrm{M} \mathrm{NaNO}_{3}$ trial.

There are limitations to this experiment, and they affected the results of the study. The friction caused by the metal of the Zahn cup is much different than that friction caused by a blood vessel. This limits the full potential of the blood reactivity to temperature to be realized, so the inhibition may not be seen in a living organism. The Zahn cup is also not reactive to vasodilation, which means the nitric oxide may have a very different result in vivo. Also, the procedure in this experiment employed gravity to promote blood flow, whereas normal circulation is propelled even against gravity. The experimental model also does not account for 
the presence of plaque in the circulatory system. Plaque would inhibit blood flow and would likely be present in a patient undergoing IH. Finally, since the experiment was conducted ex vivo, it cannot be known with certainty that this method is safe to conduct or if there are any adverse effects to the treatment.

Human error was present in this experiment, due to the extensive amount of multitasking and timing in order to conduct the experiment. When the data was analyzed, error was assumed to have made the apparent viscosity values lower than they would be under normal circulatory conditions. This is prominent in the control curve, which has values that lie outside of the normal range of human blood viscosity.

The use of sheep blood itself may also account for several errors. One inconsistency may be faster flow times due to the tightly packed structure of the sheep blood in comparison to human blood [19]. This structure may also affect the amount of the nitric oxide bound to heme groups in sheep blood. Examination of the blood samples under the microscope revealed that more sheep red blood cells (SRBCs) were contained per unit area than in the human blood samples collected. Sheep blood may also have a higher affinity for nitric oxide than human blood, which could skew the results of the experiment; but this has not been addressed in literature.

Degradation of the blood samples over time affected the extent of experimentation and may have affected the results of the $0.10 \mathrm{M} \mathrm{NaNO}_{3}$ sample. The shelf life of the blood when stored and properly cared for is approximately 28 days. However, it lasts longer when it is frozen and treated with anticoagulants. The blood employed in this experiment was not frozen and was defibrinated for testing purposes. This treatment may have degraded the RBCs more quickly than expected. The $0.10 \mathrm{M}$ concentration was the one concentration tested after the development of 
several changes in the procedure. The $0.10 \mathrm{M}$ sample needed to be retested for consistency. It is possible that the RBCs had denatured, causing faster flow than that seen in the other concentrations. This risk of degradation limited the experimental time frame. Further testing with fresh samples is needed to determine the answers to these questions.

\section{Conclusion}

In this experiment, sodium nitrate was investigated as a method to introduce nitric oxide into the circulatory system of patients who are undergoing induced hypothermia. The viscosity of the blood was measured in order to determine how the sodium nitrate would affect the flow rate. In order to lower the mortality rate associated with induced hypothermia, the flow rate of the blood as it is warmed would need to be slowed to avoid the effects of the blood rush. To determine if sodium nitrate might be used to slow the flow rate of blood, viscosity was tested at $25^{\circ} \mathrm{C}$ and $37^{\circ} \mathrm{C}$. This temperature range simulates the warming phase of induced hypothermia. Each concentration of sodium nitrate was compared at these temperatures, to determine if the turbulence was impeded.

Upon analyzing the data, the $0.11 \mathrm{M} \mathrm{NaNO}_{3}$ seemed the most effective at maintaining the blood's viscosity after raising the temperature. This concentration yielded concurrent viscosity values for both temperatures. The $0.09 \mathrm{M}$ concentration of $\mathrm{NaNO}_{3}$ also indicated some mediation with a low amount of variation in dynamic viscosity as the blood was warmed. The 0.10 $\mathrm{M} \mathrm{NaNO}_{3}$ did not seem to mediate as effectively as the other two samples tested. There was a comparative disparity between the two temperatures, which more closely resembled the untreated control. Neither the initial nor final temperature for the $0.10 \mathrm{M}$ concentration was found between the $0.09 \mathrm{M}$ and $0.11 \mathrm{M}$ concentration of sodium nitrate as they were expected to 
be. These odd results may have been caused from the degradation of the blood, a possible experimental error that suggests further study.

Due to these results, no solid conclusions can be made as to whether sodium nitrate mediated the effects of the blood rush during the warming process after induced hypothermia. The skew seen in the $0.10 \mathrm{M} \mathrm{NaNO}_{3}$ trial's data produced doubt as to whether the mediation seen in the other nitrate trials were valid. This researcher believes that a correlation is present that relates nitric oxide to a decreased blood flow due to an interaction between the hemoglobin and bound nitric oxide [15]. The correlation seems likely because none of the trials produced viscosity as low as that of the control at $37^{\circ} \mathrm{C}$. Error from replicating the $0.10 \mathrm{M} \mathrm{NaNO}_{3}$ tests close to the expiration date of the blood may have led to the degradation of the RBCs. This degradation may have reduced the ability of the hemoglobin to interact with the nitric oxide and could account for the decreased viscosities in this trial.

In order to verify that there is a correlation between decreased viscosity and intake of nitric oxide, more experiments need to be done. The experimental design should be improved to account for the human timing errors during the trials and to obtain more accurate results. One of the major concerns for this experimental design is that the amount of nitric oxide introduced into the blood is not known. It can only be assumed that higher concentrations of sodium nitrate release more nitric oxide into the blood. In future experiments, the levels of ornithine, citrulline, and arginine should be monitored in the blood before and after the addition of nitric oxide to determine the relative release of nitric oxide in the blood [25]. Further improvements can be made by testing each degree in the warming process from $32^{\circ} \mathrm{C}$ (the recommended temperature for induced hypothermia) to $37^{\circ} \mathrm{C}$ at each concentration, to create a 
better curve for correlation. The correlation between nitric oxide introduction and dynamic viscosity might be better verified using only one concentration of nitric oxide to narrow the focus of the experiment. Finally, a more precise viscometer should be used in future experiments, to better model blood flow and reduce human error associated with the fast flow times. Much more information could be gathered if the experiment were carried into a model more closely related to the conditions in vivo.

\section{Acknowledgements}

This research was made possible through the guidance of Dr. Willa Harper, professor of Chemistry at Olivet Nazarene University. Equipment utilized for this research was sourced for the Department of Chemistry and Geosciences and the Department of Biology at Olivet Nazarene University and through additional funding. This research was funded through the generous donation of Elbert Pence and Fanny Boyce, who developed this program to allow undergraduates the opportunity to conduct research. This project marks the beginning of a lifetime sharing my intrigue with the nuances and mysteries of science with the world. And for that privilege, I am not only grateful, but humbled. 


\section{References}

[1] Karnatovskaia, L. V., Wartenberg, K. E., \& Freeman, W. D. (2014, July). Therapeutic Hypothermia for Neuroprotection: History, Mechanisms, Risks, and Clinical Applications. The Neurohospitalist. Sage Publications, 4(3).

[2] Luscombe, M., \& Andrzejowski, J. (2006). Clinical applications of induced hypothermia. Continuing Education in Anaesthesia Critical Care \& Pain, 6(1), 23-27.

[3] Leao, R., Avila, P., Cavaco, R., Germano, N., \& Bento, L. (2015). Therapeutic hypothermia after cardiac arrest: Outcome predictors. Brazilian Journal of Intensive Care, 27(4), 322332.

[4] Rinehart, T. W., Merkel, M. J., Schulman, P. M., \& Hutchens, M. P. (2012). Therapeutic Hypothermia After Perioperative Cardiac Arrest in Cardiac Surgical Patients. ICU Director, 3(6), 271-278.

[5] Rajagopalan, S., Mascha, E., Na, J., \& Sessler, D. (2008). The Effects of Mild Perioperative Hypothermia on Blood Loss and Transfusion Requirement. Survey of Anesthesiology, 52(5), 238.

[6] Zinchuk, V., \& Zhadko, D. (2019). Association of endothelial nitric oxide synthase gene G894T polymorphism with blood oxygen transport. Nitric Oxide, 84, 45-49. doi:10.1016/j.niox.2019.01.007.

[7] Downey, M. (2018, November). Impede Arterial Plaque Accumulation. Life Extension. [8] European Bioinformatics Institute. (2017). Nitric Oxide. Retrieved from

[9] Jung, Y. J., Jung, J. H., Lee, D. H., Cho, Y. I., Chae, Y. J., Kang, K. P., \& Kim, W. (2018). Serum nitric oxide level correlates with serum brain natriuretic peptide and whole blood viscosity in hemodialysis patients. Nitric Oxide, 77, 1-5. doi:10.1016/j.niox.2018.03.018 https://www.ebi.ac.uk/chebi/searchId.do?chebiId=CHEBI:16480.

[10] Kapal, V., Robertson, A., \& Calufield, M. (2015). Dietary nitrate provides sustained blood pressure lowering in hypertensive patients: A randomized, phase 2, double-blind, placebo-controlled study. Dietary Nitrate Provides Sustained Blood Pressure Lowering in Hypertensive Patients: A Randomized, Phase 2, Double-blind, Placebo-controlled 
Study, 65(2), 320-327. Retrieved March 6, 2019.

[11] Sokolnicki, L. A., Strom, N. A., Roberts, S. K., Kingsley-Berg, S. A., Basu, A., \& Charkoudian, N. (2009). Skin blood flow and nitric oxide during body heating in type 2 diabetes mellitus. Journal of Applied Physiology, 106(2), 566-570. doi:10.1152/japplphysiol.91289.2008.

[12] Kapal, V., Robertson, A., \& Calufield, M. (2015). Dietary nitrate provides sustained blood pressure lowering in hypertensive patients: A randomized, phase 2, double-blind, placebo-controlled study. Dietary Nitrate Provides Sustained Blood Pressure Lowering in Hypertensive Patients: A Randomized, Phase 2, Double-blind, Placebo-controlled Study, 65(2), 320-327. Retrieved March 6, 2019.

[13] Kim, F., May, S., \& Hallstrom, A. (2019). Sodium nitrate use in out-of-hospital treatment for cardiac arrest (SNOCAT). Resuscitation, 142.

[14] Jalan, R., Olde Damink, S. W. M., ter Steege, J. C., Redhead, D. N., Lee, A., Hayes, P. C., \& Deutz, N. E. P. (2010;2011;). Acute endotoxemia following transjugular intrahepatic stent-shunt insertion is associated with systemic and cerebral vasodilatation with increased whole body nitric oxide production in critically ill cirrhotic patients. Journal of Hepatology, 54(2), 265-271. doi:10.1016/j.jhep.2010.06.042

[15] Stepuro, T. L., \& Zinchuk, V. V. (2006). Nitric oxide effect on the hemoglobin-oxygen affinity. Journal of Physiology and Pharmacology.

[16] Shen, W., Hintze, T. H., \& Wolin, M. S. (1995). Nitric Oxide. Circulation, 92(12), 35053512. doi: 10.1161/01.cir.92.12.3505

[17] Blood, A. B. (2017). The medicinal chemistry of nitrite as a source of nitric oxide signaling. Current Topics in Medicinal Chemistry, 17(15), 1758.

[18] Materials Bio Inc. (2019). Sheep Blood and Serum Products. Retrieved July 24, 2019, from http://www.quadfive.com/product-information

[19] Yeh, E., Pinsky, B. A., Banaei, N., \& Baron, E. J. (2009). Hair Sheep Blood, Citrated or Defibrinated, Fulfills All Requirements of Blood Agar for Diagnostic Microbiology Laboratory Tests. National Center for Biotechnology Information, U.S. National Library 
of Medicine, 4(7).

[20] Weschler Instruments. (2019). Zahn Viscometer Instructions For Use. Cleveland, OH: Weschler Instruments 1-2. Print.

[21] Ju, A. (2011, September 1). From paint to toothpaste, researchers capture microscopic origin of thinning and thickening fluids. Retrieved July 24, 2019, from http://news.cornell.edu/stories/2011/09/physicists-observe-particles-under-shear

[22] Hospira. (2014). Sodium Chloride Injection. Lake Forest, IL: FDA. doi: https://www.accessdata.fda.gov/drugsatfda_docs/label/2017/018090sS116lbl.pdf

[23] Vitello, D., Vitello, J., Fettiplace, M., \& Weinberg, G. (2015). Blood Density Is Nearly Equal to Water Density: A Validation Study of the Gravimetric Method of Measuring Intraoperative Blood Loss. Journal of Veterinary Medicine, 1-4. Retrieved August 12, 2019.

[24] World Book Encyclopedia. Blood Viscosity. New York, NY: World Book, 1998: 416. Print.

[25] Eijk, H. V., Luiking, Y., \& Deutz, N. (2007). Methods using stable isotopes to measure nitric oxide (NO) synthesis in the l-arginine/NO pathway in health and disease. Journal of Chromatography B, 851(1-2), 172-185. 